METALLURGY AND FOUNDRY ENGINEERING - Vol. 34, 2008, No. 2

Janusz Krawczyk*, Bogdan Pawłowski*

\title{
THE EFFECT OF NON-METALLIC INCLUSIONS ON THE CRACK PROPAGATION IMPACT ENERGY OF TOUGHENED 35B2+Cr STEEL
}

\section{INTRODUCTION}

The investigations concerning the methods of restricting the content of non-metallic inclusions in structural steels as well as modification of the morphology of these inclusions for the improvement of the properties of such steels are still carried out by many researchers [1-4]. Such research is being performed in spite of the fact, that today's metallurgical technologies assure the content of non-metallic inclusions on the level required by corresponding technical standards (for example PN-64/H-04510, DIN 50 602, and ASTM E45-97 standards) [5]. Despite the fact, that many research works [6-8] describe the role of nonmetallic inclusions in initiation of cracking or in fatigue wear [8-10], there is still a need to investigate the relation between non-metallic inclusions content and parameters describing the impact energy of steels, independent of notch geometry (for example in the case of the samples for impact energy testing). Such research is also important for the sake of verification of the proposed theories of the influence of non-metallic inclusions on the properties of steels [11, 12] and numerical models based on these theories [13]. One of such parameters (material constant) can be for example a critical coefficient of stress intensity $\mathrm{K}_{\mathrm{IC}}$ [12]. However, this coefficient describes the crack resistance under static conditions and at plane state of strain. To obtain such a parameter describing crack resistance under dynamic conditions, it is necessary to apply Gulaev's interpretation of it [14], allowing for division of the energy of nucleation and development of the crack during impact testing.

The aim of this research is to describe the influence of non-metallic inclusions content in $35 \mathrm{~B} 2+\mathrm{Cr}$ toughened steel on the impact energy of crack development, described assuming linear dependence between notch-root radius and the impact energy of crack nucleation, as described by Gulaev [14].

* Ph.D.: Faculty of Metals Engineering and Industrial Computer Sciences, AGH University of Science and Technology, Kraków, Poland; jkrawczy@metal.agh.edu.pl; jkrawczy@ruczaj.pl 


\section{MATERIAL FOR TESTING}

The research was performed on $35 \mathrm{~B} 2+\mathrm{Cr}$ steel used for screws, delivered by three various suppliers. The chemical compositions of ingots are given in Table 1. After spheroidizing annealing, samples taken from the ingots were toughened. Austenitizing was performed at the temperature of $860^{\circ} \mathrm{C}$ for 60 minutes. Endothermic protective atmosphere of $+5^{\circ} \mathrm{C}$ dew-point and $0.4 \%$ carbon potential was applied. Hardening was performed in Hartenol $70 \mathrm{~S}$ oil, and tempering was done at $450^{\circ} \mathrm{C}$ for 100 minutes. The microstructures of the investigated toughened steels are show on Figure 1. It can be noticed, that the microstructures of steels obtained from different suppliers are very similar. The hardness of these steels is also similar (see Tab. 2).

Table 1. The chemical composition (weight \%) of investigated steels

\begin{tabular}{|c|c|c|c|c|c|c|c|c|c|c|c|c||}
\hline Steel & $\mathrm{C}$ & $\mathrm{Si}$ & $\mathrm{Mn}$ & $\mathrm{P}$ & $\mathrm{S}$ & $\mathrm{Cr}$ & $\mathrm{Mo}$ & $\mathrm{Ti}$ & $\mathrm{Cu}$ & $\mathrm{Al}$ & $\mathrm{B}$ & $\mathrm{N}$ \\
\hline no. 1 & 0.37 & 0.07 & 0.75 & 0.009 & 0.010 & 0.27 & 0.008 & 0.030 & 0.030 & 0.036 & 0.0040 & 0.0070 \\
\hline no. 2 & 0.38 & 0.08 & 0.73 & 0.010 & 0.005 & 0.28 & 0.006 & 0.035 & 0.046 & 0.042 & 0.0033 & 0.0077 \\
\hline no. 3 & 0.37 & 0.08 & 0.68 & 0.008 & 0.012 & 0.24 & - & - & 0.050 & 0.042 & 0.0027 & 0.0048 \\
\hline
\end{tabular}

a)

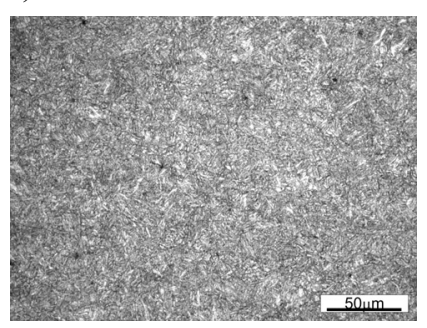

b)

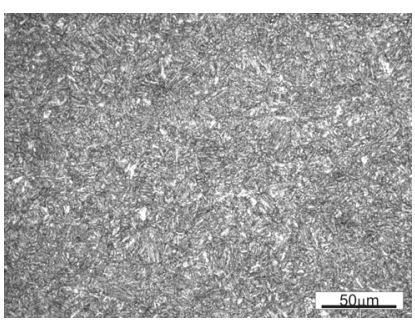

c)

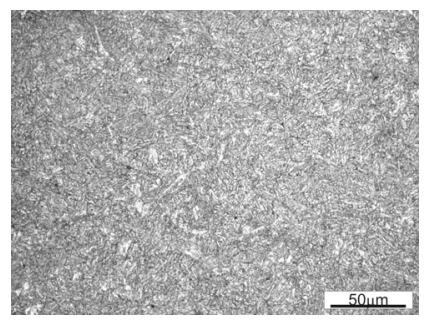

Fig. 1. Microstructure of investigated steels: a) steel no. 1; b) steel no. 2; c) steel no. 3

Table 2. The hardness of investigated steels after toughening

\begin{tabular}{|c|c|c||}
\hline Steel no. 1 & Steel no. 2 & Steel no. 3 \\
\hline $366_{-9}^{+11}$ HV 30 & $358_{-15}^{+15}$ HV 30 & $360_{-5}^{+11}$ HV 30 \\
\hline
\end{tabular}

\section{EXPERIMENTAL PROCEDURE}

Impact tests were carried out on $10 \times 10 \times 55 \mathrm{~mm}$ samples. Two notch geometries were applied: both were $2 \mathrm{~mm}$ deep, but with different notch-root radius $(0.25 \mathrm{~mm}$ and $1 \mathrm{~mm})$. Samples were deformed on Charpy hammer (maximum energy of $150 \mathrm{~J}$ ). All the tests were performed at room temperature. Five impact tests were performed for each steel and for each notch geometry. 
The fraction of non-metallic inclusions $(\mathrm{Vv})$ was evaluated on polished cross-sections using "point method". The measurements of non-metallic inclusion content was performed on two randomly chosen samples taken from each sort of supplied steels, using 55 projections for each sample. The number of points in the projected nets was 441. The samples were analyzed under the magnification of $630 x$.

Basing on the morphology of non-metallic inclusions (according to PN-64/H-04510 standard), they were devided (identified) into oxides, sulfides, nitrides and other inclusions described in this study as exogenous inclusions.

\section{RESULTS AND DISCUSSION}

Sample pictures of polished cross-sections of specimens with visible non-metallic inclusions are shown on Figure 2.

a)

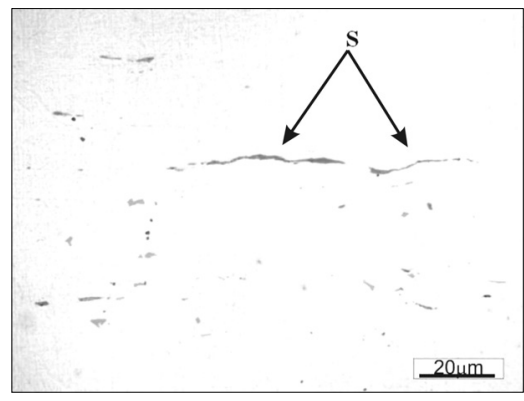

b)

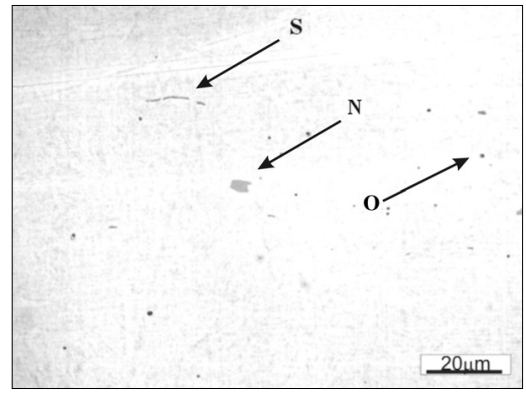

c)

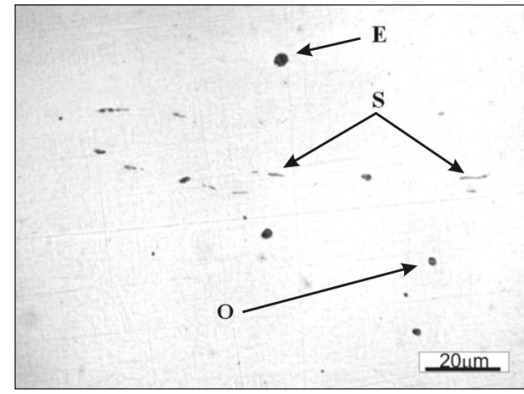

Fig. 2. The areas of high non-metallic inclusions concentration in steel samples: a) steel no. 1; b) steel no. 2; c) steel no. 3. The longer side of pictures is parallel to the processing direction

Chosen non-metallic inclusions were marked as follows: $\mathrm{O}$ - oxides, $\mathrm{S}-$ sulfides, $\mathrm{N}$ - nitrides, $\mathrm{E}$ - exogenous inclusions. It can be observed, that brighter colour was characteristic for inclusions of nitrides and so called "correct" (angular) shape (Fig. 2b). Nitrides were present in small number in the investigated steels and their distribution may be considered as uniform. Sulfides were more often present in a form of precipitations elongated along the direction of deformation. They were darker as compared to the nitrides and brighter as compared to the oxides (Fig. 2a-c). The most difficult part was to distinguish oxide inclusions from exogenous inclusions. It was assumed, that oxides should be considered as 
fine dispersion inclusions (Fig. 2b, c). The classic oxide strings were not observed. Nonmetallic inclusions of large dimension, characterized by "fuzzy" shape, were considered as exogenous inclusions (Fig. 2c). The inclusions, described above as exogenous inclusions, may partly be endogenous inclusions of silicates, but identifying them basing on the observations of polished cross-section, with a use of the light microscope, is difficult. For simplicity, these inclusions are considered as exogenous in this work.

Summarized fraction of non-metallic inclusions as well as after dividing them into particular kind of inclusions in steels comming from the particular supplier is shown in Table 3.

Table 3. Non-metallic inclusions contribution (volume \%) in investigated steels

\begin{tabular}{|c|c|c|c|c|c||}
\hline Steel & $\begin{array}{c}\text { non-metallic } \\
\text { inclusions }\end{array}$ & oxides & sulfides & nitrides & $\begin{array}{c}\text { exogenous } \\
\text { inclusions }\end{array}$ \\
\hline no. 1 & $0.299 \pm 0.032$ & $0.157 \pm 0.012$ & $0.091 \pm 0.041$ & $0.024 \pm 0.011$ & $0.027 \pm 0.009$ \\
\hline no. 2 & $0.270 \pm 0.015$ & $0.136 \pm 0.006$ & $0.095 \pm 0.023$ & $0.027 \pm 0.003$ & $0.012 \pm 0.006$ \\
\hline no. 3 & $0.210 \pm 0.012$ & $0.115 \pm 0.017$ & $0.062 \pm 0.023$ & $0.016 \pm 0.001$ & $0.016 \pm 0.006$ \\
\hline
\end{tabular}

The impact energy of crack development was evaluated assuming, according to Gulaev theory, a linear dependence between notch-root radius and crack nucleation energy. For this purpose, an average values of the impact energy determined in impact tests for the samples of different notch-root radius were used. The macroscopic picture of fracture surfaces of samples is shown on Figure 3. The pictures, that were used for the approximation of the impact energy of the crack development for steels delivered by particular supplier is shown on Figure 4. Steel No 2 was characterized by the greatest impact energy of crack development.

Having the measurements of the content of non-metallic inclusions as well as the values of impact energy of crack development, the relationship between them was searched (Fig. 5-9).

There was no clear relationship between a total fraction of non-metallic inclusions and impact energy of crack development (Fig. 5). Similar situation was in the case of relationship between the oxide content and and the energy of the crack development (Fig. 6). The advantageous influence of the content of sulfides (Fig. 7) and nitrides (Fig. 8) on the impact energy of the crack development was proved. This phenomenon may be explained by the ductility of sulfides and their elongation in the direction perpendicular to the plane of the fracture during impact test. Such a morphology of the sulfides can restrict the propagation of the crack. It is, however, difficult to explain such an influence of nitrides due to their properties and morphology. Maybe it should not be considered in respect to the aluminum bounded in a form of inclusions, but in respect to the aluminum dissolved in the alloy matrix. In the case of a large number of unbounded in nitrides aluminum atoms present in the alloy matrix, they may segregate to the grain boundaries, causing weakening if these areas. Such an interpretation of the results of this research seems to be in agreement with the analysis of the chemical composition of the investigated steels, especially in respect to the aluminum content and nitrogen content (see Table 1). As opposed from mentioned above sorts of non-metallic inclusions, exogenous inclusions strongly decrease the impact energy of the crack development (Fig. 9). 
A

a)

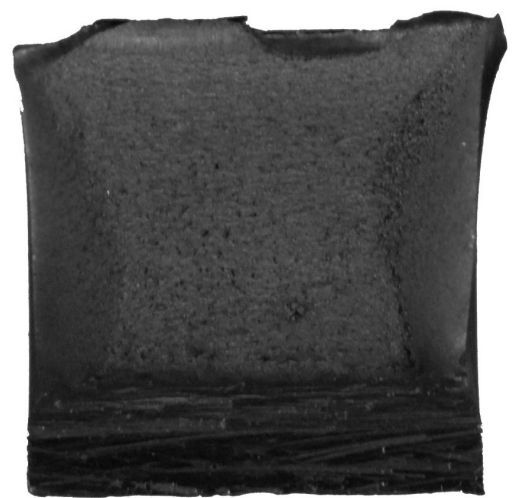

b)

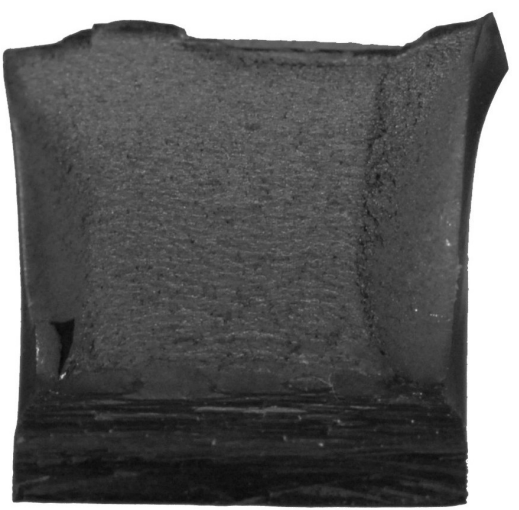

c)

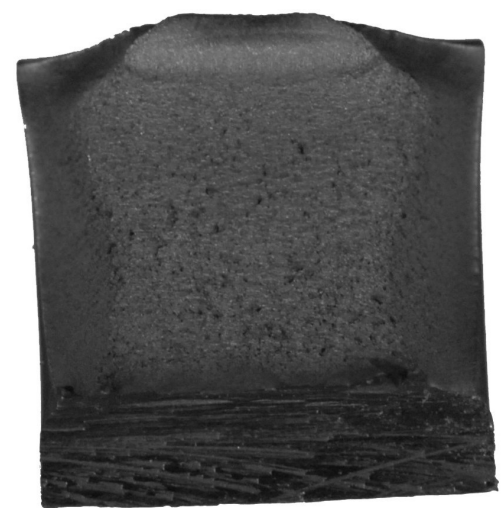

$\mathrm{B}$
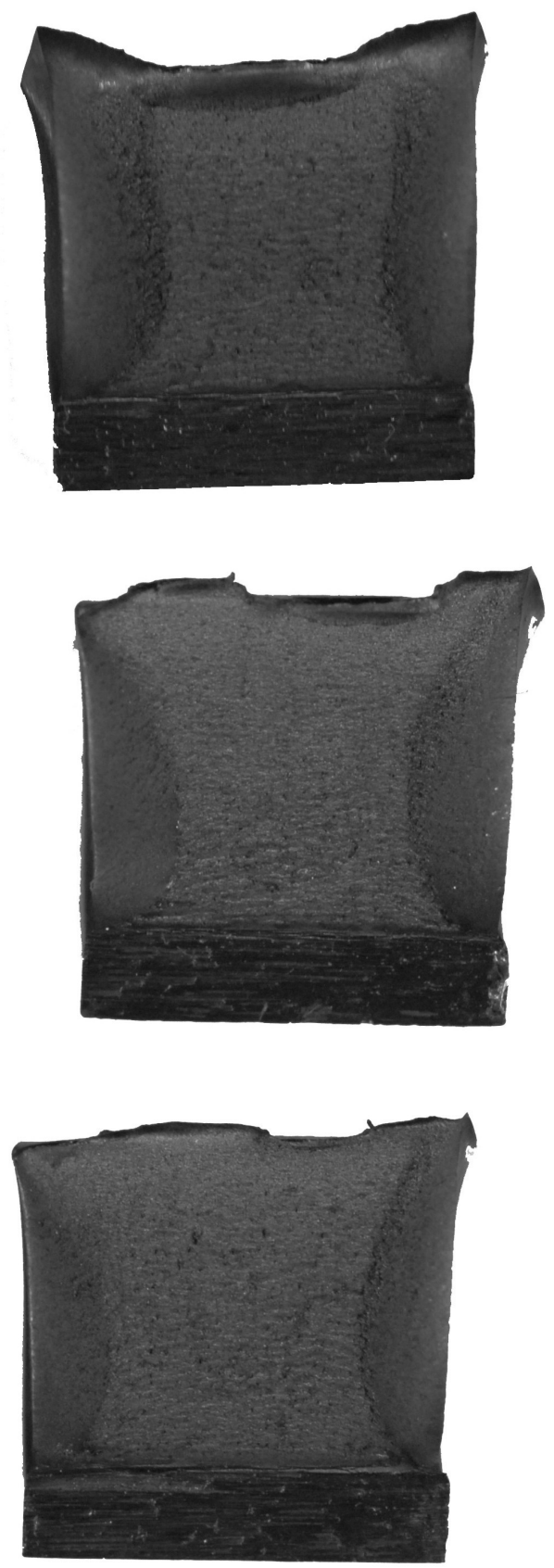

Fig. 3. The fracture surfaces after impact toughness tests of investigated steels according to samples notch: a) steel no. 1; b) steel no. 2; c) steel no. 3; A) notch radius $-1 \mathrm{~mm}$; B) notch radius $-0.25 \mathrm{~mm}$ 
a)

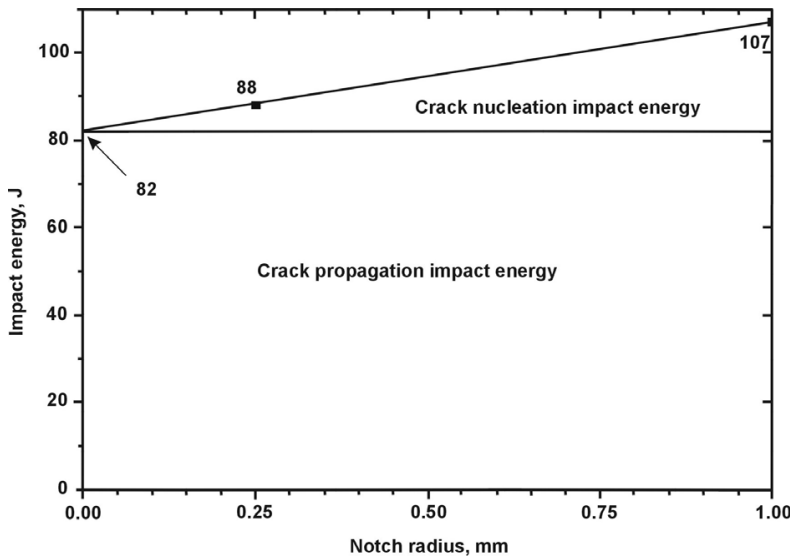

b)

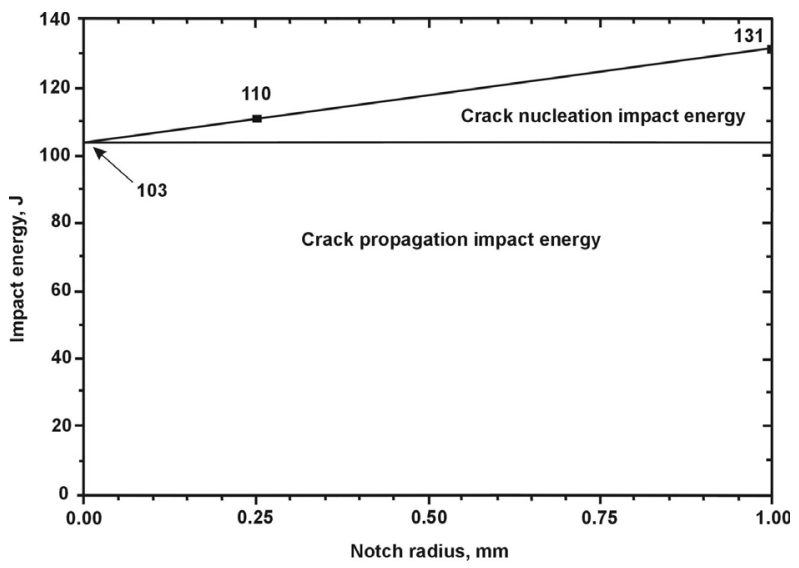

c)

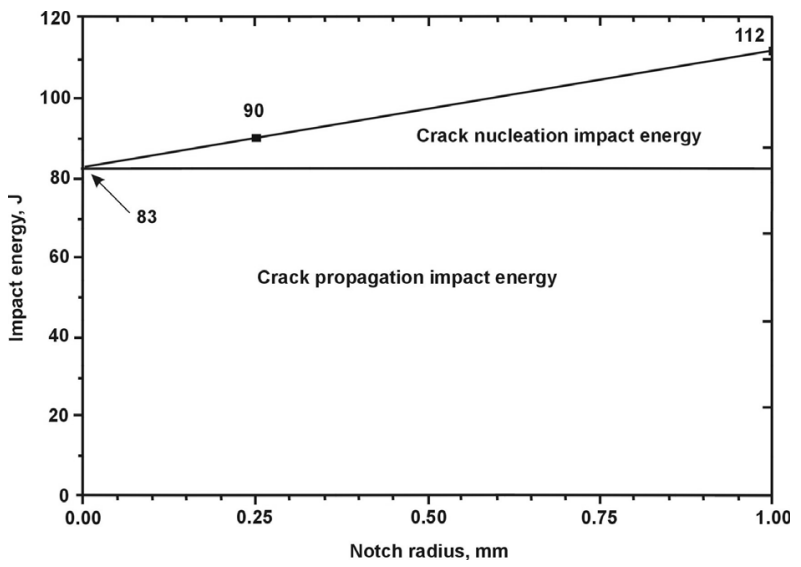

Fig. 4. A method of determination of the impact energy of crack development based on the work needed for impact test samples breaking according to Gulajev rule [14]. Samples of different notchroot radius: a) steel no. 1; b) steel no. 2; c) steel no. 3 


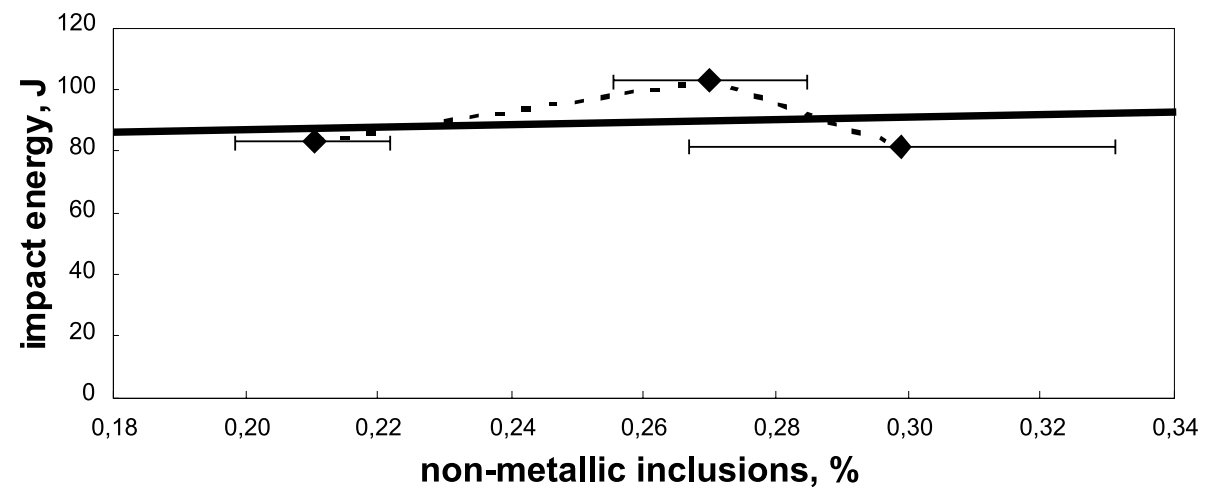

Fig. 5. The effect of fraction of non-metallic inclusions on the crack propagation energy of investigated steels

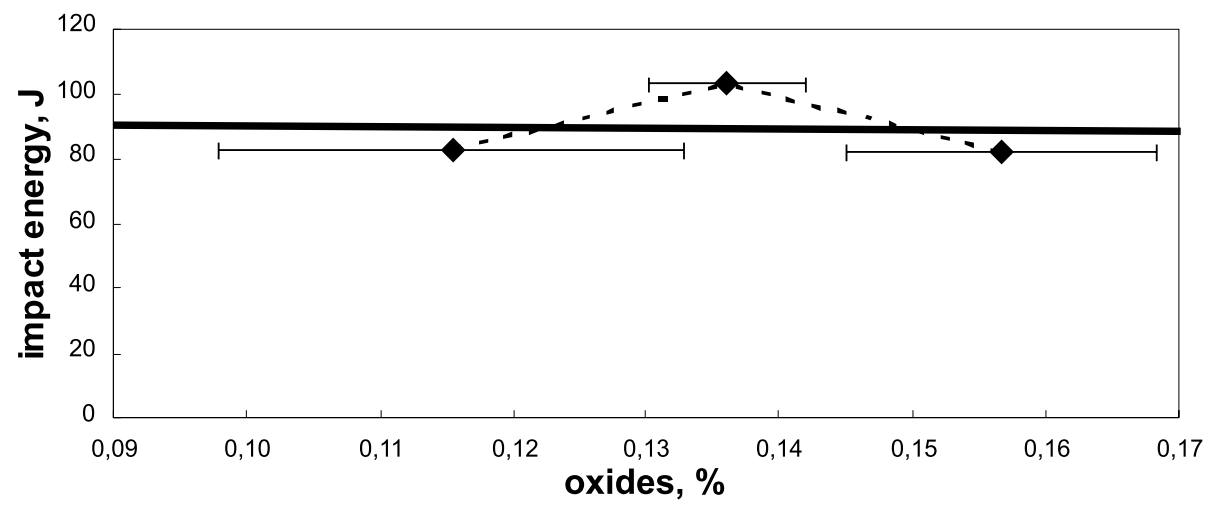

Fig. 6. The effect of fraction of oxide inclusions on the crack propagation energy of investigated steels

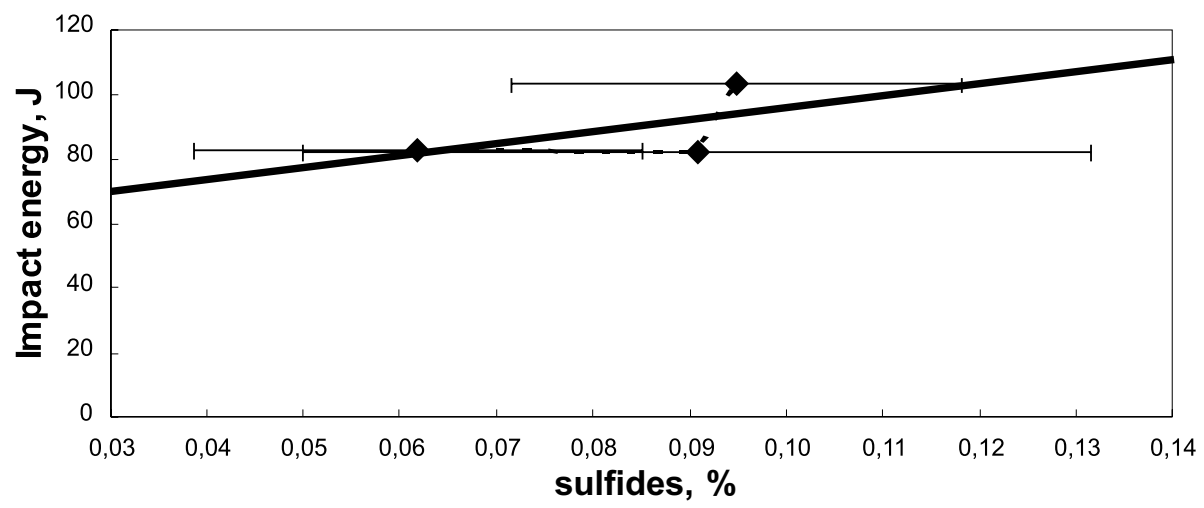

Fig. 7. The effect of fraction of sulfide inclusions on the crack propagation energy of investigated steels 


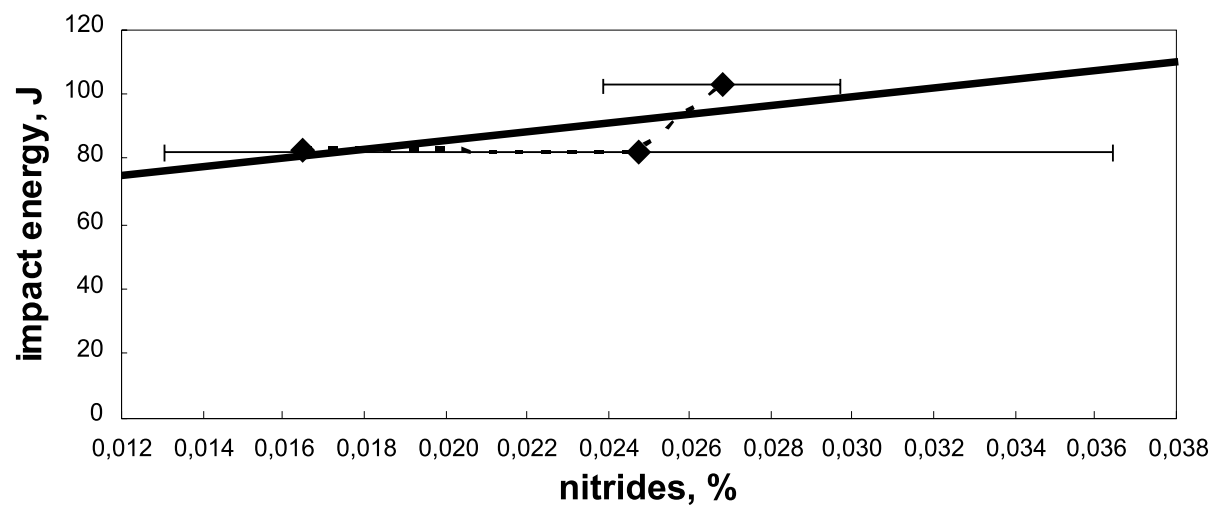

Fig. 8. The effect of fraction of nitride inclusions on the crack propagation energy of investigated steels

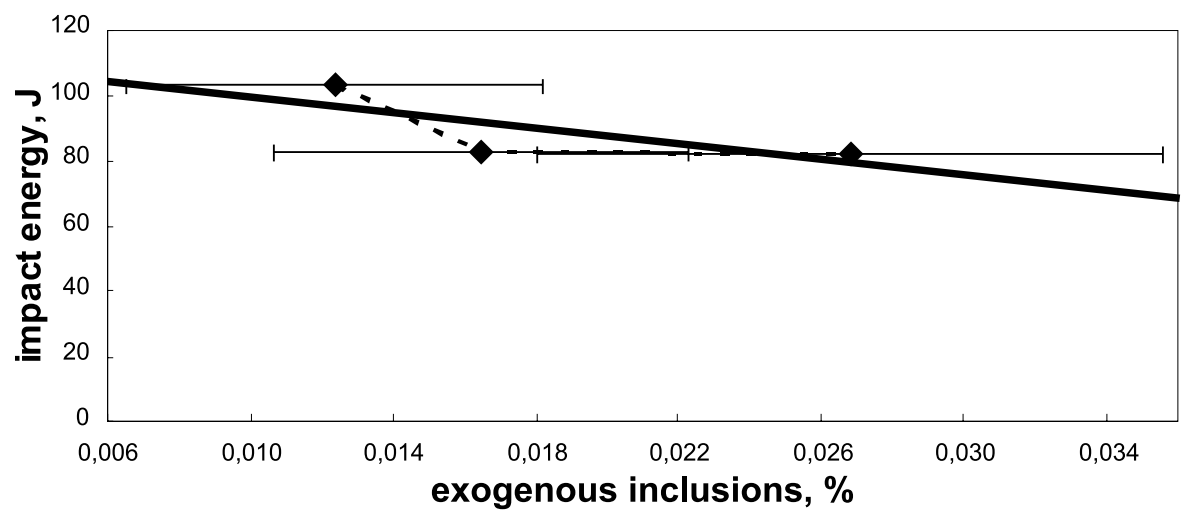

Fig. 9. The effect of fraction of exogenous inclusions on the crack propagation energy of investigated steels

\section{CONCLUSIONS}

Obtaining similar microstructure and hardness in steels delivered by three different suppliers, characterized by different content of non-metallic inclusions, with application of linear approximation of the relation between notch-root angle and the impact energy of the crack development, allowed to derive the following conclusions:

1. The differences in non-metallic inclusions content, in the range given by technical standard, have an influence on the impact energy of the crack development in toughened $35 \mathrm{~B} 2+\mathrm{Cr}$ steel.

2. A clear evidence of the influence of total content of non-metallic inclusions on the impact energy of crack development in the investigated toughened steel was not observed. 
3. The influence of oxide inclusions (forming no oxide strings in the structure) on the impact energy of the crack development in $35 \mathrm{~B} 2+\mathrm{Cr}$ toughened steel was also not noticed.

4. The precipitations of sulfides in a fibrous form (elongated), of the axis perpendicular to the notch, make the impact energy of $35 \mathrm{~B} 2+\mathrm{Cr}$ toughened steel greater.

5. Decrease of the content of aluminum dissolved in the alloy matrix, connected with the increase of the content of nitrides content (greater content of nitrogen in relation to aluminum content), influences the increase of the impact energy of the crack development in toughened $35 \mathrm{~B} 2+\mathrm{Cr}$ steel.

6. Large non-metallic inclusions (described in present work as exogenous inclusions) decrease the impact energy of the crack development in toughened $35 \mathrm{~B} 2+\mathrm{Cr}$ steel.

Koelner Śrubex S.A. company is greatly appreciated for supplying the samples for this research. The authors of this study would also like to thank MSc Agnieszka Drozd for help in this research.

\section{REFERENCES}

[1] Lis T., Różański P.: Inclusions engineering in liquid steel. Hutnik, Wiadomości Hutnicze 72, 5 (2005) 256264 (in Polish)

[2] Różański P., Paduch J.: Modification of non-metallic inclusions in steels with enhanced machinability. Archives of Metallurgy 48, 3 (2003) 285-307

[3] Kang Y.-B., Kim H.S., Zhang J., Lee H.-G.: Practical application of thermodynamics to inclusions engineering in steel. J. of Physics and Chemistry of Solids 66, 2-4 (2005) 219-225

[4] Li J.-H., Chen S.-H., Xi T.-H., Chen X.: Effect of micro-alloyed Ti on inclusions modification. J. of Iron and Steel Research 14, 5, supp. 1 (2007) 320-324

[5] Lis T.: Characterization of typical non-metallic inclusions in clean steels. Hutnik, Wiadomości Hutnicze 75, 3 (2008) 106-109 (in Polish)

[6] Sojka J., Jérôme M., Sozańska M., Váňová P., Rytírová L., Jonšta P.: Role of microstructure and testing conditions in sulphide stress cracking of X52 and X60 API steels. Materials Science and Engineering A, 480, 1-2 (2008) 237-243

[7] Elkoca O., Cengizler H.: Cracking during cold forming process of rear brake component. Engineering Failure Analysis 15, 4 (2008) 295-301

[8] Yang Z.G., Li S.X., Zhang J.M., Zhang J.F., Li G.Y., Li Z.B., Hui W.J., Weng Y.Q.: The fatigue behaviors of zero-inclusion and commercial $42 \mathrm{CrMo}$ steels in the super-long fatigue life regime. Acta Materialia 52, 18 (2004) 5235-5241

[9] Jha Abhay K., Sreekumar K., Mitkal M.C.: Metallurgical studies on a failed EN 19 steel shear pin. Engineering Failure Analysis 15, 7 (2008) 922-930

[10] Beretta S., Ghidini A., Lombardo F.: Fracture mechanics and scale effects in the fatigue of railway axles. Engineering Fracture Mechanics 72, 2 (2005) 195-208.

[11] Costa e Silva A.: Thermodynamic aspects of inclusion engineering in steel. Rare Metals 25, 5 (2006) $412-$ 419

[12] Pacyna J.: Physical metallurgy of tools steels cracking. Metallurgy and Foundry Engineering 120 (1988) 134-148 (in Polish) 
[13] Niezgodziński T., Kubiak T., Młodkowski A.: Phenomenon of lamellar tearing in numerical calculation. Zeszyty Naukowe Politechniki Świętokrzyskiej. Mechanika 73 (2001) 233-239 (in Polish) .

[14] Gulaev A.P.: Разложение ударной вязкости на ее составляющие по данным испытания образцов с разным надрезом (Rozloženie udarnoj vjazkosti na ee sostavljajuščie po dannym ispytanija abrazcov s raznym nadrezom - The decomposition of impact energy on the components on the ground of tests of impact strength samples with different notches). Zavodskaja Laboratorija 33 (1967) 473-475 (in Russian).

Received

December 2008 